\title{
THE IMPACT OF OPERATING CASH FLOW AND CURRENT RATIO ON THE PROFITABILITY IN CONSTRUCTION INDUSTRY
}

\section{Daniela Pordea*}

Doctoral School of Economics and Business Administration, West University of Timişoara, Romania E-mail: danapordea@gmail.com

\section{Delia David}

"Vasile Goldiș" Western University of Arad, Romania

E-mail:david_delia2003@yahoo.com

\section{Dorel Mates}

West University of Timişoara, Romania

E-mail: mates.doloro60@yahoo.com

\section{(Received: October 2019; Accepted: December 2019; Published: March 2020)}

Abstract: The quality of works and a good reputation on the market are the main factors that lead to the success of a construction business. That is why most of the projects carried out in this sector involve the provision of performance guarantees which are mainly constituted by retaining the amounts from each payment. This impacts the cash, but also the liquidity ratios of the entities. The purpose of our research is to analyze the influence of the operating cash flow and the current liquidity ratio on the profitability in the case of construction companies. For this, we have developed a linear regression model on crosssection financial data related to a single reporting year and obtained from construction companies in western Romania. The results we have obtained did not reveal statistical significance for the exogenous variables used in the model. However, we consider it important to deepen the problem of cash flows and the ability of construction companies to meet their short-term obligations in the context of retaining performance guarantees. Further research in this regard based on panel data for several financial periods could provide relevant results

Keywords: construction, guarantees, cash flow, current ratio, ROE

JEL Codes: M41, M21, C01

${ }^{*}$ Corresponding author: Daniela Pordea.E-mail: danapordea@gmail.com

Copyright (C) 2020 The Author(s). Published by VGWU Press

This is an Open Access article distributed under the terms of the Creative Commons Attribution License - Non Commercial - NoDerivs License (http://creativecommons.org/licenses/by-nc-nd/3.0/) which permits unrestricted $\underline{\text { use, distribution, and reproduction in any medium, provided the original author and source are credited. }}$ 
Pordea, D., David, D., Mateș, D., (2020)

The impact of operating cash flow and current ratio on the profitability in construction industry

\section{Introduction}

The construction industry is a key sector of the economy, being the most important provider of jobs in Europe (Ortiz, Catells \& Sonnemann, 2009, p. 29). The possible financial problems of the entities in this field can have serious consequences on the completion of their projects and can be reflected at the macroeconomic level. For this reason, the financial analysis of the construction companies mainly concerns their ability to generate cash, as well as to fulfill their obligations towards third parties.

The construction activity has particularities compared to other industries. The businesses are mobile and personalized and the investment projects are characterized by a high level of complexity and uncertainty, due to their long-term scope. The risks associated with these activities are thus higher than in the other sectors of the economy.

A characteristic of this industry is providing the quality of works, which in contractual terms translates into the retention of performance guarantees. The most widespread guarantee method consists of successive deductions from the invoiced values. The payment of the retained amounts is delayed until the end of the project, thus affecting companies' operating cash flow, with possible serious consequences especially in the case of small entities, which may face difficulties in maintaining positive cash flow.

The retained funds are presented in the financial statements as non-current assets and are intended to cover any quality defects that may occur during the contractual warranty period. Thus, the structure of the entity's assets is modified by decreasing the current assets, with a direct impact on the current liquidity ratio.

In this context, our research objective was to examine the influence of the operating cash flow and the current ratio on the financial performance of construction entities, thus contributing to the research in the financial accountancy field.

As for the structure of our paper, we have started with a review of the relevant literature on the topic of performance guarantees and cash flow in relation to the companies' financial indicators. The next section reveals the methodology of our research, including the collected data and the research hypotheses, while the last part highlights and analyzes the results we have obtained. Finally, we have presented our conclusions and directions for future research.

\section{Literature review}

The influence of the retained funds as performance guarantees on the financial indicators of construction entities has been very little addressed in the literature. Hughes, Hillebrandt \& Murdoch (1998) have indicated some practical solutions for financial protection for the companies in this sector, taking into account the 
Pordea, D., David, D., Mateş, D., (2020)

The impact of operating cash flow and current ratio on the profitability in construction industry

contractual constraints regarding the performance guarantees of the works. In a later paper, the authors have also analyzed the cost of the retained funds according to the duration of works and have revealed a significantly greater impact on the cash flow in the case of subcontractors who carry out small works and have to wait for the completion of the main project in order to encash their amounts (Hughes, Hillebrandt \& Murdoch, 2000).

In October 2017, the government of the United Kingdom has published a complex survey conducted by Pye Tait Consulting (2017) based on questionnaires. The purpose of this study was to analyze the impact of guarantees retention on the construction business. Their findings point out that these practices negatively influence the development of companies and the level of investments in this sector, reducing the economic competitiveness. From a financial perspective, these retained funds increase the need for external financing as well as the level of indebtedness, all the more so since in practice, the guarantees are often returned only partially or not at all at the end of the period for which they were established.

Many authors have bent on the causal relationships between cash flows and financial ratios (Giacomino \& Mielke, 1993, Brush, Bromiley \& Hendrickx, 2000, Park \& Jang, 2013). Limam \& Mohammed (2018) have approached the influence of the operating cash flow on the profitability of the listed companies in Nigeria. Using Return on Assets (ROA) as a dependent variable, the authors have noticed a statistically insignificant impact, but the developed model has revealed a direct and significant influence of the operating cash flow on the Return on Equity (ROE).

In a study conducted on a sample of 42 listed Indian companies in the field of real estate and construction, Mittal \& Lavina (2018) have shown that Return on Equity (ROE) is the most important impact factor on financial security in this business.

On the other hand, the possible causal relationship between the liquidity and the profitability of the commercial companies has not been the subject of much academic research. The current ratio reflects the ability of companies to meet their current obligations that are due within one year. Keeping this indicator at an optimum level implies ensuring an adequate level of current assets, which must be above that of short-term liabilities. Following this reasoning, we can anticipate that an increase in the current liquidity will lead to an increase in the profitability of the activity, but too high a level of this indicator can be a sign of over liquidity, with possible adverse effects on the profitability. In other words, an economic entity can carry out a profitable activity without necessarily being liquid. This assertion is confirmed by the analysis conducted by Eljelly (2004), who has shown that the correlation between current liquidity and profitability is negative, although ensuring the liquidity of a company is essential for increasing its long-term wellbeing and performance, both during times of crisis and in favorable economic situations. 
Pordea, D., David, D., Mateș, D., (2020)

The impact of operating cash flow and current ratio on the profitability in construction industry

\section{Research methodology and sample data}

For our study, we have used a sample of 29 financial statements for the year 2017, which we have obtained individually from small and medium-sized entities operating on the western construction market of Romania.

Based on the literature and the reasonings presented in the previous section, we have formulated the following research hypotheses:

H1: There is a positive correlation between the level of the operating cash flow and the return on equity for the construction entities.

H2: There is a negative correlation between the current ratio and the return on equity for the construction entities.

To test our research hypotheses, we have run a multiple linear regression model in the RStudio computer program (RStudio Incorporated, 2019) applied on crosssection data (a series of economic entities and a single reporting year), as denoted in equation (1) below:

(1) $\mathrm{ROE}_{\mathrm{i}}=\alpha+\beta 1 \times \mathrm{CFO}_{\mathrm{i}}+\beta 2 \times \mathrm{CR}_{\mathrm{i}}+\varepsilon$

where:

$\mathrm{ROE}_{\mathrm{i}}$ - is the Return on Equity for entity $\mathrm{i}$;

$\mathrm{CFO}_{\mathrm{i}}-$ is the Operating Cash Flow for entity $\mathrm{i}$;

$\mathrm{CR}_{\mathrm{i}}-$ is the Current Ratio for entity $\mathrm{i}$;

$\beta$ - is the estimated relationship between the endogenous variable (ROE) and the explanatory variables (CFO and $\mathrm{CR}$ );

$\varepsilon-$ is the cumulative effect of other factors that influence the endogenous variable.

We have used the accounting information obtained from the financial statements to determine the indicators that were the basis of the analysis.

The Return on Equity (ROE) expresses the entities' efficiency of using their equity in order to obtain profit. For determining this ratio, we have used the calculation formula presented by Robu, Anghel \& Șerban (2014, p. 366):

(2) $\mathrm{ROE}=\frac{\text { Net Income }}{\text { Shareholder's Equity }}$ 
Pordea, D., David, D., Mateș, D., (2020)

The impact of operating cash flow and current ratio on the profitability in construction industry

Cash flows are the basis for the analysis of the financial equilibrium, of the way in which an entity can finance its activity and ensure the continuity in its operation. To determine the operating cash flow, we have used the methodology developed by Brîndescu-Olariu (2014), which allows the use of the indirect method of calculation, based exclusively on the data in the balance sheet and the profit and loss account. We have resorted to this option as our sample consists of small and medium-sized companies, which do not have the legal obligation to present separately the Cash Flows Statements. The method of calculating the operating cash flow according to this method is shown below:

(+) Total revenues

(-) Decrease of provisions

$(+)$ Increase of deferred income

(-) Decrease of deferred income

$(+)$ Increase of reserves

(-) Profit appropriation

$(+)$ Increase of retained earnings

(-) Increase of accounts receivable

$(+)$ Decrease of accounts receivable

$=$ Cash income from operations

(+) Total expenses

(-) Impairment losses on non-current assets

(-) Increase of provisions

$(+)$ Decrease of reserves

$(+)$ Decrease of retained earnings

$(+)$ Increase of inventories

(-) Decrease of inventories

(-) Decrease of deferred expenses

$(+)$ Increase of deferred expenses

(-) Interest expense

(-) Increase of non-financial debts

$(+)$ Decrease of non-financial debts

$=$ Cash outflows from operations

Operating Cash Flow (5) = Cash income from operations (3) - Cash outflows from operations (4)

The current ratio is the most widely used liquidity ratio in financial analyzes and expresses an entity's ability to pay its short-term debts based on its current assets,

26 sciendo Studia Universitatis "Vasile Goldis" Arad. Economics Series Vol 30 Issue 1/2020 ISSN: 1584-2339; (online) ISSN: 2285 - 3065

Web: publicatii.uvvg.ro/index.php/studiaeconomia. Pages $22-32$ 
Pordea, D., David, D., Mateș, D., (2020)

The impact of operating cash flow and current ratio on the profitability in construction industry

according to Robu, Anghel \& Șerban (2014, p. 449). This ratio can be calculated by comparing the current assets to the current liabilities:

$$
\mathrm{CR}=\frac{\text { Current Assets }}{\text { Current Liabilities }}
$$

The values thus determined for the independent variable and the explanatory ones in our regression model are summarized in Table 1.

Table 1 Values of variables of the multiple linear regression model

\begin{tabular}{|c|c|c|c|}
\hline Company & Return on Equity & Operating Cash Flow & Current Ratio \\
\hline 1 & 0 & 737.606 & 1.601673 \\
\hline 2 & 0 & 5.271 .233 & 27.78983 \\
\hline 3 & 0.395143 & -3.209 .768 & 1.02935 \\
\hline 4 & 0 & -1.869 & 0.94306 \\
\hline 5 & -0.09697 & 43.663 & 0.716438 \\
\hline 6 & 0 & -982 & 0.007608 \\
\hline 7 & 0.133307 & -388.160 & 0.898812 \\
\hline 8 & 0 & -27.842 & 0.069757 \\
\hline 9 & 0 & -18.204 & 0.330837 \\
\hline 10 & 0 & -47.296 & 0.341062 \\
\hline 11 & 0.213602 & 25.380 & 12.5506 \\
\hline 12 & 0 & -18.579 & 0.009282 \\
\hline 13 & 0.925691 & 8.625 & 1.797952 \\
\hline 14 & 0 & 186 & 0.267794 \\
\hline 15 & 0.442236 & 634.171 & 4.64659 \\
\hline 16 & 1.004092 & 132.064 & 2.493777 \\
\hline 17 & 0.409789 & 408.719 & 5.567034 \\
\hline 18 & 0.00215 & -639.313 & 7.606095 \\
\hline 19 & 0.307389 & 412.921 & 4.684759 \\
\hline 20 & 1.006413 & 359.652 & 0.995857 \\
\hline 21 & 0 & -26.835 & 0.89202 \\
\hline 22 & 0.21008 & 6.354 .168 & 1.317373 \\
\hline 23 & -3.1937 & 50.819 & 0.931833 \\
\hline 24 & 0.638334 & 103.078 & 3.855798 \\
\hline 25 & 0.039789 & 88.380 & 7.861821 \\
\hline 26 & 0.029886 & -715.544 & 1.111143 \\
\hline 27 & 0.007821 & 22.048 & 4.463203 \\
\hline 28 & 0 & 151 & 0.015524 \\
\hline 29 & -0.08818 & 34.279 & 0.395559 \\
\hline
\end{tabular}

Source: author's projection 
Pordea, D., David, D., Mateș, D., (2020)

The impact of operating cash flow and current ratio on the profitability in construction industry

To obtain a set of non-dimensional estimators and eliminate the scale effect, we have reprocessed the variables of the regression by using the normalization method around their arithmetic mean, through the formula:

$$
\text { vi' }=\frac{\mathrm{vi}-\mathrm{Mvi}}{\mathrm{si}}
$$

Where:

vi' - is the normalized value of the variable $\mathrm{i}$;

vi - is the value of the variable $\mathrm{i}$;

$\mathrm{Mvi}$ - is the arithmetic mean of the variable $\mathrm{i}$;

si - is the mean square deviation (standard deviation) of the variable $i$, determined at the sample level.

The values of the regression variables resulting from the normalization procedure are shown in Table 2.

Table 2 Normalized values of regression variables

\begin{tabular}{|c|r|r|r|}
\hline Company & Return on Equity & Operating Cash Flow & \multicolumn{1}{c|}{ Current Ratio } \\
\hline 1 & -0.11627 & 0.244023 & -0.30194 \\
\hline 2 & -0.11627 & 2.963417 & 4.402476 \\
\hline 3 & 0.441944 & -2.12372 & -0.40475 \\
\hline 4 & -0.11627 & -0.19953 & -0.42025 \\
\hline 5 & -0.25326 & -0.17222 & -0.46096 \\
\hline 6 & -0.11627 & -0.199 & -0.5883 \\
\hline 7 & 0.072048 & -0.43124 & -0.4282 \\
\hline 8 & -0.11627 & -0.21511 & -0.57713 \\
\hline 9 & -0.11627 & -0.20933 & -0.53023 \\
\hline 10 & -0.11627 & -0.22678 & -0.5284 \\
\hline 11 & 0.185481 & -0.18319 & 1.664914 \\
\hline 12 & -0.11627 & -0.20956 & -0.588 \\
\hline 13 & 1.191447 & -0.19324 & -0.26668 \\
\hline 14 & -0.11627 & -0.1983 & -0.54156 \\
\hline 15 & 0.508472 & 0.18198 & 0.245044 \\
\hline 16 & 1.302203 & -0.1192 & -0.14169 \\
\hline 17 & 0.462634 & 0.046747 & 0.410392 \\
\hline 18 & -0.11324 & -0.58189 & 0.776687 \\
\hline 19 & 0.317974 & 0.049268 & 0.251901 \\
\hline 20 & 1.305483 & 0.017316 & -0.41077 \\
\hline 21 & -0.11627 & -0.21451 & -0.42942 \\
\hline 22 & 0.180506 & 3.612991 & -0.35301 \\
\hline 23 & -4.628 & -0.16793 & -0.42227 \\
\hline & & & \\
\hline & & & \\
\hline
\end{tabular}


Pordea, D., David, D., Mateș, D., (2020)

The impact of operating cash flow and current ratio on the profitability in construction industry

\begin{tabular}{|c|r|r|r|}
\hline Company & Return on Equity & Operating Cash Flow & Current Ratio \\
\hline 24 & 0.785499 & -0.13658 & 0.102987 \\
\hline 25 & -0.06006 & -0.1454 & 0.822625 \\
\hline 26 & -0.07405 & -0.62762 & -0.39006 \\
\hline 27 & -0.10523 & -0.18519 & 0.212101 \\
\hline 28 & -0.11627 & -0.19832 & -0.58688 \\
\hline 29 & -0.24084 & -0.17785 & -0.51861 \\
\hline
\end{tabular}

Source: author's projection

\section{Results and discussions}

In Table 3 we have highlighted the results of the multiple linear regression model run in the Rstudio computer program:

Table 3 Normalized values of regression variables

\begin{tabular}{ccccc}
\hline \hline Residuals: & & & & \\
\hline \hline Min & $\mathbf{1 Q}$ & Median & $\mathbf{3 Q}$ & Max \\
-4.6026 & -0.0919 & -0.0802 & 0.3095 & 1.3354 \\
\hline \hline Coefficients: & Estimate & Std. Error & $\mathbf{t}$ value & $\operatorname{Pr}(>|\mathbf{t}|)$ \\
(Intercept) & $-2.044 \mathrm{e}-10$ & $1.923 \mathrm{e}-01$ & 0.000 & 1.000 \\
CFO & $-2.871 \mathrm{e}-02$ & $2.231 \mathrm{e}-01$ & -0.129 & 0.899 \\
CR & $7.155 \mathrm{e}-02$ & $2.231 \mathrm{e}-01$ & 0.321 & 0.751 \\
\hline \hline
\end{tabular}

Residual standard error: 1.036 on 26 degrees of freedom

Multiple R-squared: 0.003972, Adjusted R-squared: -0.07265

F-statistic: 0.05185 on 2 and $26 \mathrm{DF}$, p-value: 0.9496

Source: author's projection

The value of the t-student test is well below the threshold of 2 for each of the three explanatory variables that we have tested, so they do not exert a statistically significant influence on the independent variable (Return on Equity). This assertion is also reinforced by the value of the significance threshold illustrated by $\operatorname{Pr}(>|\mathrm{t}|)$, which exceeds $10 \%$, thus not being statistically accepted.

Moreover, the explanatory capacity of the model is very low in the light of the value recorded by the Adjusted R-squared coefficient, of -0.07265 .

In conclusion, the results of the study did not reveal statistical significance for our research hypotheses. In other words, our model did not prove a correlation between the explanatory variables (the Operating Cash Flow and the Current Ratio) and the independent or endogenous variable (the Return on Equity). 
Pordea, D., David, D., Mateș, D., (2020)

The impact of operating cash flow and current ratio on the profitability in construction industry

\section{Conclusions, limits and directions of future research}

The purpose of the present paper was to analyze the impact that the Operating Cash Flow and the Current Ratio exerts on the financial profitability of the construction companies. A cash shortage is one of the major causes of failure in the construction projects (Al-Issa \& Zayed, 2007) and deepening the problem of cash flows and liquidity ratios in this sector is a necessity, considering the particularities of the economic activity in terms of costs, quality, safety and deadlines for work execution. The results we have obtained did not reveal statistical significance for the used explanatory variables.

One of the limits of our research lies in the fact that the analysis was performed on cross-section data, related to a single reporting year. We believe that further research can take into account several financial periods in order to obtain relevant results. At the same time, a questionnaire-based approach applied in the Romanian construction industry might consider the sector's perception of the way in which the performance guarantees influence the companies' financial balance and might contribute to the development of this industry so important to the economy of a country.

Another difficulty we have encountered in our research process was obtaining the sets of financial statements on which we have based our analysis and which have been requested individually from the entities. This problem resides in the fact that in Romania only listed companies have the obligation to publish their financial statements in full. However, the calculation of the economic indicators needed in our study has involved the analysis of the reports in their entirety.

In the context in which the accounting systems in general and the accounting of the construction activity, in particular, are in full progress and technological transformation, the role of the accounting profession in creating added value for business will intensify. The information presented by the financial statements is essential to ensure the viability of the economic entities based on correct and efficient managerial decisions. Therefore, the improvement of the methods and techniques of financial analysis becomes an indispensable condition for researchers and the academic world.

\section{Acknowledgements}

The authors thank the anonymous reviewers and editor for their valuable contribution.

\section{Funding}

This research received no specific grant from any funding agency in the public, commercial, or not - for - profit sectors. 
Pordea, D., David, D., Mateș, D., (2020)

The impact of operating cash flow and current ratio on the profitability in construction industry

\section{Author Contributions}

D.P. conceived the presented idea, designed the model and analyzed the data. D.P. and D.D. performed the calculations. D.D. reviewed the relevant literature. D.M. supervised the entire research and provided a critical revision. All authors discussed the results and commented on the paper.

\section{Disclosure Statement}

The authors have not any competing financial, professional, or personal interests from other parties.

\section{References}

1. Al-Issa, A. \& Zayed, T., (2007), Projects Cash Flow Factors - Contractor Perspective, Proceedings of ASCE Construction Research Congress, Bahamas, 5-8 Mai 2007, pp. 489-497

2. Brîndescu-Olariu, D., (2014), Model de prezentare a fluxurilor de numerar dezvoltat prin metoda indirectă, Managementul Intercultural, XVI (30), pp. 6-20.

3. Brush, T.H., Bromiley, P., \& Hendrickx, M., (2000), The Free Cash Flow Hypothesis for Sales Growth and Firm Performance, Strategic Management Journal, 21, pp. 455-472

4. Hughes, W., Hillebrandt, P.M., \& Murdoch, J., (1998), Financial Protection in the UK Building Industry: Bonds, Retentions and Guarantees, London, UK: Taylor \& Francis

5. Hughes, W., Hillebrandt, P.M., \& Murdoch, J., (2000), The Impact of Contract Duration on the Cost of Cash Retention, Construction Management and Economics, 18, pp. 11-14

6. Eljelly, A., (2004), Liquidity - Profitability Tradeoff: An Empirical Investigation in an Emerging Market, International Journal of Commerce and Management, 14 (2), pp. 48-61

7. Giacomino, D.E., \& Mielke, D.E., (1993), Cash Flows: Another Approach to Ratio Analysis, Journal of Accountancy, 175(3), pp. 54-86

8. Limam, M., \& Mohammed, A.S., (2018), Operating Cash Flow and Corporate Financial Performance of Listed Conglomerate Companies in Nigeria, Journal of Humanities and Social Science, 23(2), pp. 1-11

9. Mittal, S., \& Lavina, (2018), The Determinant of Financial Distress in Indian Real Estate and Construction Industry, Gurukul Business Review, 14, pp. 6-11

10. Ortiz, O., Catells, F., \& Sonnemann, G., (2009), Sustainability in the Construction Industry: A Review of Recent Developments Based on LCA, Construction and Building Materials, 23, pp. 28-39 
Pordea, D., David, D., Mateș, D., (2020)

The impact of operating cash flow and current ratio on the profitability in construction industry

11. Park, K., \& Jang, S., (2013), Capital Structure, Free Cash Flow, Diversification and Firm Performance: A Holistic Analysis, International Journal of Hospitality Management, (33), pp. 51-63

12. Pye Tait Consulting, (2017), Retentions in Construction Industry [online]. Retrieved from https://assets.publishing.service.gov.uk, Accessed on 02 March 2019

13. Robu, V., Anghel, I., \& Șerban, E.C., (2014), Analiza economico-financiară a firmei, Editura Economică, București, Romania, pp. 501-503

14. RStudio Incorporated, (2019), RStudio (1.2.1335) [computer program], Available at: https://www.rstudio.com/products/rstudio/ Accessed on 25 August 2019 